\title{
Regional Analysis of Fish Farms in Ghana: A Stochastic Meta- Frontier Approach
}

\author{
Edward Ebo Onumah $^{1, *}$ (D) Felix Larry Essilfie ${ }^{1}$ \\ ${ }^{1}$ University of Ghana, Department of Agricultural Economics and Agribusiness, Post Office Box LG 68
}

\section{Article History \\ Received 28 July 2020 \\ Accepted 04 September2020 \\ First Online 17 September 2020 \\ Corresponding Author \\ Tel.: +00233542835782 \\ E-mail: eeonumah@ug.edu.gh}

\section{Keywords}

Regional gap

Technical efficiency

Productivity

Stochastic meta-frontier

\begin{abstract}
Using a cross-section data of 320 observations, this paper employs the meta-frontier stochastic model to estimate and compare the productivity, efficiency levels and their determining factors among fish farms in Greater Accra, Ashanti, Western and Volta regions of Ghana. Findings reveal that productivity of output response to individual production factors employed in Greater Accra and Western regions exhibit increasing return to scale, whilst their counterpart in the Volta and Ashanti regions display decreasing return to scale. Some exogenous factors are also estimated to influence variance in efficiency. Fish farms in the Volta and Greater Accra regions are comparatively more technically efficient than their similitudes in the Western and Ashanti regions. Thus, whilst policy considerations to enhance efficiency and productivity of fish farms in the country are paramount, increasing fish output to the potential maximum could easily be achieved among farms in the Volta and Greater Accra regions than fish farms in the Western and Ashanti regions
\end{abstract}

\section{Introduction}

Fisheries play an important role in Ghana's economic growth and development. However, the demand for fish has always exceeded the country's production (Quagrainie \& Chu, 2019). Accordingly, the country has over the years attempted to curtail the excess demand over supply by importing frozen and canned fish products. This does not motivate smallholder fish farmers to be competitive on the basis of prices since imported frozen fish is relatively affordable. Akuffo \& Quagrainie (2019) note that the per capita fish consumption in Ghana is about $22 \mathrm{~kg}$ which makes the nation one of the highest fish consuming countries in Africa, indicating a good market opportunity for fish merchandise. Despite the overwhelming taste for fish ( $60 \%$ share of protein food), existing data reveals that fish farming's contribution to the overall fish supply in Ghana is very minimal (Amenyogbe et al., 2018). Total annual fish production which mainly consists of the marine and the inland fisheries has relatively been declining over the years, whilst the population of the country continues to rise significantly over the same period. FAO (2016) notes that marine fisheries production has been declining from about 420,000 tonnes in 1999 to almost 202,000 tonnes in 2014. This situation demonstrates the need for immediate action to be considered to mitigate the fish consumption gap especially at a time when fish farming has become one of the major alternatives to boost fish production.

If fish farming can flourish in Ghana and in effect execute it responsibility towards enhancing food security and providing alternative livelihood support for people, all stakeholders including the government, input dealers, farmers, processors, and consumers must operate together. That notwithstanding, there is also an 
integral premise that fish farming requires more resources to reach their maximum level of production. Nonetheless, studies have revealed that enhancing fish production is obtained by advancement in output per factor inputs, which can be achieved through an efficient combination of factor resources. Considering various determining factors influencing fish farming, enhancing the efficiency of already existing input resources to the farmers is most important (Crentsil \& Essilfie, 2014).

Several works have been carried out on the efficiency of fish farms in the country. Nonetheless, none of these researchers has analytically compared the efficiency scores among regions where fish farming is predominant. For instance, a study by Onumah, Brümmer, \& Horstgen-Schwark (2010) adopted the conventional efficiency technique and assumed a homogenous technology and regional fixed effect condition by applying the Stochastic Frontier Analysis (SFA) to evaluate the technical efficiency of fish farmers in Ghana. The conventional SFA estimation procedure possesses a limitation which is common in instances where fish farms from different regions are compared especially in a country where regional productivity levels of fish output are not adequately estimated. The Metafrontier Analysis (MFA) is more appropriate to compare regional productivities and efficiencies of fish farms because it specifies a potential frontier for all farms to be a basis for examining all individual frontiers. Thus, the contribution of this paper is to examine and note the similarities or differences of technical efficiency levels as well as the determining factors of fish farms using the meta-frontier approach in four regions of Ghana (Greater Accra, Ashanti, Western, and Volta), whilst taking into consideration regional differences.

\section{Materials and Methods}

\section{Conceptual Framework}

This paper constructs four different frontiers for Greater Accra, Ashanti, Western, and the Volta regions of Ghana to measure the level of fish output for the individual regions compared to the possible maximum yield characterized by the meta-frontier. It is impossible to infer from the individual production frontiers that farms producing in one region are more efficient than those producing in other regions. The meta-frontier model as demonstrates in Figure 1, allows such a conclusion by assuming a model that overarches the output boundaries of individual regions. It also enables regional disparity to be obtained from farms in dissimilar geographical areas in relation to the industry's potential performance (Battese, Rao, \& O’Donnell, 2004).

\section{Theoretical Framework for the Study}

The stochastic meta-frontier approach is an improved method over the conventional stochastic technique to analyse the technical efficiencies of farm/firms that operate in different geographical areas or use different technologies (Battese, Rao, \& O'Donnell, 2004). This follows the meta-technology approach by Hayami \& Ruttan (1970).

Considering $r$ regions in the fish farming industry, a conventional stochastic approach is specified as:

$$
Y_{i}^{(\mathrm{r})}=f\left(x_{i} ; \beta^{(\mathrm{r})}\right) \cdot \exp ^{v_{i}^{(\mathrm{r})}-u_{i}^{(\mathrm{r})}} \equiv \exp ^{x_{i} \beta^{(\mathrm{r})}+v_{i}^{(\mathrm{r})}-u_{i}^{(\mathrm{r})}}
$$

where the variable $Y_{i}$ denotes the production of the ith unit in the $r t h$ region; ${ }^{x_{i}}$ denotes an inputs vector as used by the ith unit for the $r$ th region; $\beta^{(r)}$ is a parameter vector for the input factors in the frontier model for the $r$ th geographical area; $v_{i}^{(r)}$ is the symmetric random term which is assumed as identically and independently distributed with a zero mean and a constant variance - $N\left(0, \sigma_{v^{(r)}}^{2}\right)$, autonomous of the inefficiency term $u_{i}^{(r)}$ that is also assumed as a truncation of the $N\left(\mu_{i}^{(r)}, \sigma_{u^{(r)}}^{2}\right)$ dispersions such that the mean $\mu_{i}^{(r)}$ is specified as:

$$
\mu_{i}^{(r)}=\delta_{m}^{(r)} Z_{m i}
$$

The specification of the $\mu_{i}^{(r)}$ is employed in Battese \& Coelli (1995) to analyze the determinants of technical efficiency. To verify if the various regions share different geographical or environmental characteristics, the paper uses the likelihood ratio test (LR) to compute the difference in the log-likelihood value for the pooled regions and the sum of the log-likelihood values from the individual region. The outcome is an indication of whether the meta-frontier is the best technique for comparing the technical efficiencies across the regions. In this paper, the meta-frontier production model is expressed as:

$$
Y_{i}^{*}=f\left(x_{i} ; \beta^{*}\right)=e^{x_{i} \beta^{*}}, i=1,2,3, \ldots, N_{r}
$$

where $\beta^{*}$ stands for the parameters of the metafrontier model such that $x_{i} \beta^{*}$ is greater than $x_{i} \beta^{r}$. This expression notes the dominance of meta-frontier over all the regional frontiers. The actual output for the ith farm characterised by the stochastic frontier of the $r t h$ region in equation (1) is stated in terms of the metafrontier of model (3) as: 


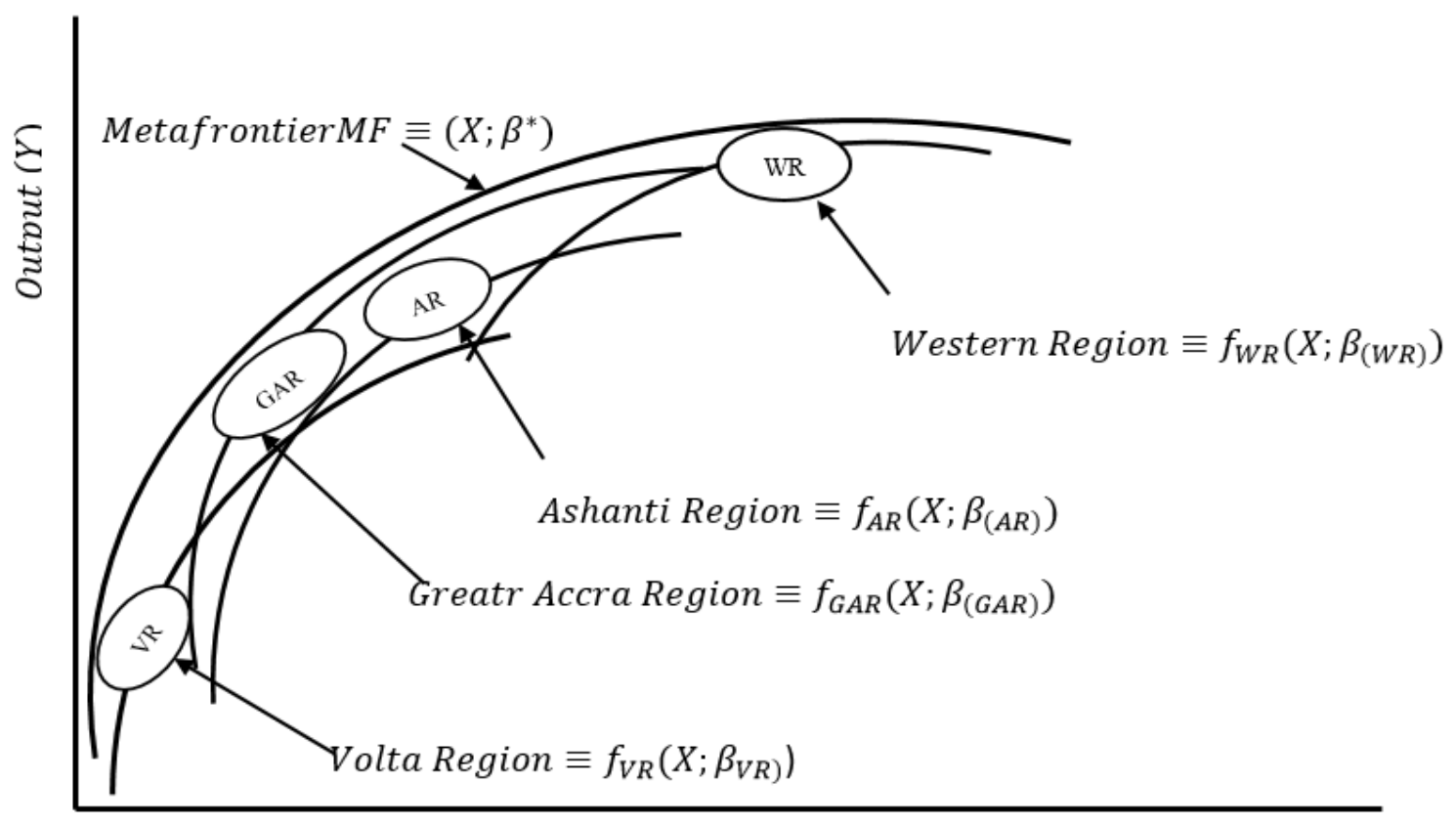

Adapted from Battese, Rao, O’Donnell (2004).

Input (x)

Figure 1. Meta-frontier model for the four regions of Ghana.

$$
Y_{i}=\exp ^{u_{i}^{r}} \cdot \frac{\exp ^{x_{i} \beta^{r}}}{\exp ^{x_{i} \beta^{*}}} \cdot \exp ^{x_{i} \beta^{*}+v_{i}^{r}}
$$

Following O’Donnell, Rao, \& Battese (2008), the paper obtains the meta-frontier coefficients by the reduced sum of deviation squares of the meta-frontier from the regional frontiers in the optimization problem in (6):

$$
\begin{aligned}
& \operatorname{MinL} \equiv \sum_{i=1}^{N}\left(x_{i} \beta^{*}-x_{i} \beta^{r}\right)^{2} \\
& \text { s.t } \quad x_{i} \beta^{*} \geq x_{i} \beta^{r}
\end{aligned}
$$

This technique corresponds to the least-squares criterion mechanism (Battese, Rao, \& O'Donnell, 2004). The optimization problem in (6) is a quadratic programming approach that uses simulation (considered by the paper) or bootstrapping methods to obtain the standard errors of the meta-frontier parameters.

\section{Empirical Model Specification}

The paper employs the stochastic meta-frontier framework which incorporated fish farm managerial ability, farm operational factors and environmental factors (Battese \& Coelli, 1992; and 1995). This paper estimates both the regional level frontiers that allow the parameters to be different for the four regions (Greater Accra, Ashanti, Western and Volta regions) ${ }^{1}$ and the frontier from the combined data. The translog stochastic frontier function that accommodates regional and environmental differences is specified as: 


$$
\operatorname{Ln} Y_{i}=\beta_{0}+\sum_{n=1}^{4} \beta_{n} \ln x_{n i}+1 / 2 \sum_{n=1}^{4} \sum_{k=1}^{4} \beta_{n k} \ln x_{n i} \ln x_{k i}+\left(v_{i}\right)-\left(u_{i}\right) \quad \mu_{i}=\delta_{0}^{r}+\sum_{m=1}^{10} \delta_{m}^{r} Z_{m i}
$$

where $L n$ represents natural log; $i$ refers to the $i^{\text {th }}$ fish farm; $Y_{i}$ represents the quantity of fish harvested which is measured in kilogram per hectare $(\mathrm{Kg} / \mathrm{ha}) ; x_{1}$ indicates quantity of fingerlings (fry) used during the production period in kilograms per hectare $(\mathrm{Kg} / \mathrm{ha}) ; x_{2}$ represents the quantity of pelleted feed in $\mathrm{Kg} / \mathrm{ha}$ used throughout the production period; $x_{3}$ denotes the number of people who are employed to work on the fish farm throughout the production period and it is measured in man-days $/ \mathrm{ha}^{1} ; x_{4}$ captures the cost of other inputs employed in the production period in Ghana Cedis/ha and $\beta_{s}$ are parameters to be obtained. Both the output and input factors have been normalized per hectare to nullify the size effects. Following the work of Onumah, Brümmer, \& Horstgen-Schwark (2010), the researchers assumed equal depth for all ponds considered in the study.

\section{Output Elasticity of Inputs}

In the translog production functional form, the estimated coefficients do not have direct interpretation because the responsiveness of the various inputs to output (elasticities) has mathematical relationships with both the first- and second-order derivatives together with the number of input variables available (Onumah, Al-Hassan, \& Onumah, 2013). However, when the output and the various input resources are scaled by their respective means, the first-order parameters in equation (7) eventually represent the partial elasticities.

$$
\varepsilon_{y}=\frac{\partial \ln E\left(\mathrm{Y}_{i}\right)}{\partial \ln x_{n i}}=\left\{\beta_{n}+\beta_{n n} \ln x_{n i}+\sum_{i=1}^{4} \beta_{n k} \ln x_{k i}\right\}=\beta_{n}
$$

The subscripts $n$ and $k$ represent the inputs $n$ andk, $\varepsilon_{y}$ is the elasticity of output, $x(s)$ are input variables and the $\beta^{\prime} s$ are coefficients to be estimated. The sum of the partial elasticities is the overall or total elasticity $(\varepsilon)$ which is an indication of return to scale. If $(\varepsilon)>1$, it implies that there is increasing returns-toscale (IRS); if $(\varepsilon)<1$, it connotes decreasing returns-toscale (DRS); and if $(\varepsilon)=1$, it indicates that there is a constant returns-to-scale (CRS).

\section{Determinants of Technical Efficiency}

To explain variabilities in the technical and metafrontier efficiency scores of sampled fish farms in all four regions, the factors hypothesized as the determinants are specified in the model (9) as: where $\delta$ is the parameter to be estimated; and $\mu_{i}$ is the mean of the truncated asymmetric (non-negative) term. The $\mu_{i}$ is assumed to establish the technical inefficiency in production; $r$ remains as defined in the model (1) and $\delta_{0}$ represents the constant term in the equation. $Z$ is a vector of exogenous variables explaining variation in efficiency and are described as follows: $\boldsymbol{Z}_{\mathbf{1}}$ : refers to age of main decision maker captured in years; $Z_{2}$ : Gender variable measured as dummy where a male primary decision maker is given a value of 1 and a female primary decision maker is given a value of $0 ; \boldsymbol{Z}_{3}$ : Education is defined as the number of years of formal education the primary decision maker has obtained and it is captured in years; $\boldsymbol{Z}_{\mathbf{4}}$ : Size of the primary decision-makers' household (measured in numbers); $\boldsymbol{Z}_{\mathbf{5}}$ : Major Occupation, measured as dummy where a full time fish farmer is given a value of 1 and a part-time fish farmer, a value of $0 ; \boldsymbol{Z}_{\mathbf{6}}$ : Pond Type, measured as dummy ( $1=$ cage system and $0=$ earthen pond system); $\boldsymbol{Z}_{7}$ : Farm ownership dummy, measured as $1=0 w n$ farm and $0=$ otherwise; $\boldsymbol{Z}_{\mathbf{8}}$ : Fish Famers Association (FFA) dummy measured as $1=$ member of fish farm association and $0=$ otherwise; $\boldsymbol{Z}_{\mathbf{9}}$ : Extension service dummy, measured as 1 for access and 0 for no access; $\boldsymbol{Z}_{\mathbf{1 0}}$ : Access to ready market (farm gate purchase) dummy, captured as $1=$ access to ready market and $0=$ otherwise.

The inefficiency model generates variance parameters which is specified as $\sigma^{2}=\sigma_{u}^{2}+\sigma_{v}^{2}$. Following the works of Battese \& Coelli (1992); and Addison, Ohene-Yankyera, \& Fredua-Antoh (2016), the gamma $(\gamma)$ which is variance ratio, relates the variance of $u_{i}$ to total variance of both $u_{i}$ and $v_{i}$, and can be expressed as $\gamma=\sigma_{u}^{2} /\left(\sigma_{u}^{2}+\sigma_{v}^{2}\right)$, where $0 \leq \gamma \leq 1$. The closer the value of $\gamma$ to 1 , the more the deviation of observed output from the frontier is as a result of inefficiency factors. However, if the value of $\gamma$ is close to 0 then deviation of output from the frontier may be due more to the stochastic factors.

\section{Data Description}

The paper employs data obtained from a survey conducted in two fish farming districts each in Greater Accra, Ashanti, Western and Volta regions of Ghana. The regions are principally fish farm based. The mean annual rainfall pattern within the four regions ranges between $895 \mathrm{~mm}-1506 \mathrm{~mm}$ with mean annual temperature between $26^{\circ \mathrm{C}}-27^{\circ \mathrm{C}}$. Ali \& Nakamura (1999) notes that 
optimal relative humidity as a result of favorable temperature and desirable rainfall can have positive consequences on the productivity and efficiency of fish farming. Aside from fish farming, farmers in the four regions are food crop farmers who grow staple crops including maize, yam, cocoyam, plantain, cassava, and rice; other tree crops including coffee and oil palm; and fruit crops including citrus and avocado.

A multi-stage sample approach is employed for the paper. In stage one, two (2) fish farming districts are purposively picked from the four regions. The chosen districts are Dangbe West and Dangbe East in the Greater Accra Region; Keta and Hohoe districts in Volta Region; Tarkwa Municipal and Prestea Huni-Valley in the Western Region, and Amansie West and Amansie East Districts in Ashanti Region. In stage two, two (2) fish farming communities are selected randomly from the two (2) fish farming districts in each of the four regions, based on interviews with officials of regional fisheries commission. In the final stage, about 20 fish farms are selected randomly from the communities making a total of about 40 farms in each district. The paper uses 80 fish farms, selected from specific region, making a total of 320 farms after data cleaning. Cross-sectional information is obtained from the selected fish farms using a well-structured questionnaire. A pilot test of the survey instrument is first done with the intention to descriptively confirm the validity, reliability, appropriateness of the questions and anticipated responses by the fish farmers. All issues detected in relation to the questionnaire during the pilot survey are addressed and considered for the main data collection.

Using the maximum likelihood estimator, this paper considers the Ox program with the SFAMB package (Brümmer, 2015) to obtain the parameter estimates.

\section{Results and Discussion}

In this paper, several null hypotheses are tested to assess the fitness and correctness of the specified model used for each regional and the pooled data. Findings from the hypotheses testing are presented in Table 1.

The outcome of the first hypothesis rejects the Cobb-Douglas in preference to the translog model for the individual study regions and also for the combined data, demonstrating that incorporation of the squared and cross product terms provide accurate and consistent estimates for policy implications. Results from the second hypothesis are rejected for all the models revealing that there is the presence of inefficiency in all the regional and the combined data. In the third hypothesis, the notion that inefficiency effects are not stochastic is rejected for all the models, implying that the stochastic frontier function is the most appropriate model for all the regional as well as the pooled data. Finally, the principal null hypothesis of great concern to this paper that the regional-level data are obtained from a one frontier function under similar geographical and environmental conditions is rejected, implying that the four regional frontier models for fish farms in Ghana are not similar. Hence, the meta-frontier approach is the most appropriate technique for this paper.

The maximum-likelihood parameters for regional frontiers, in addition to the meta-frontier are presented in Table 2. Findings from the paper show that the estimated sigma-square of $0.75,0.82,0.83,0.89$ and

Table 1. Hypotheses tests for the regional and meta-frontier model assumptions

\begin{tabular}{|c|c|c|c|}
\hline Null Hypothesis & LR Statistics $(\lambda)$ & $\begin{array}{c}\text { Critical } \\
\text { Value } \\
(0.001)\end{array}$ & Decision \\
\hline \multicolumn{4}{|l|}{$\mathrm{H}_{0}: \beta_{\mathrm{ij}}=0$} \\
\hline Greater Accra & 35.62 & 29.59 & $\mathrm{H}_{0}$ Rejected \\
\hline Ashanti & 76.70 & 29.59 & $\mathrm{H}_{0}$ Rejected \\
\hline Western & 67.02 & 29.59 & $\mathrm{H}_{0}$ Rejected \\
\hline Volta & 43.36 & 29.59 & $\mathrm{H}_{0}$ Rejected \\
\hline Pooled & 89.88 & 29.59 & $\mathrm{H}_{0}$ Rejected \\
\hline \multicolumn{4}{|l|}{$\mathrm{H}_{0}: \gamma=\delta_{0}=\delta_{1}=\delta_{2}=\ldots, \ldots,=\delta_{10}=0$} \\
\hline Greater Accra & $79.72^{\mathrm{a}}$ & $32.20^{\mathrm{b}}$ & $\mathrm{H}_{0}$ Rejected \\
\hline Ashanti & $80.82^{a}$ & $32.20^{\mathrm{b}}$ & $\mathrm{H}_{0}$ Rejected \\
\hline Western & $48.91^{a}$ & $32.20^{\mathrm{b}}$ & $\mathrm{H}_{0}$ Rejected \\
\hline Volta & $56.48^{a}$ & $32.20^{b}$ & $\mathrm{H}_{0}$ Rejected \\
\hline Pooled & $405.09^{a}$ & $32.20^{\mathrm{b}}$ & $\mathrm{H}_{0}$ Rejected \\
\hline \multicolumn{4}{|l|}{$\mathrm{H}_{0}: \gamma=0$} \\
\hline Greater Accra & $12.84^{\mathrm{a}}$ & $9.50^{b}$ & $\mathrm{H}_{0}$ Rejected \\
\hline Ashanti & $22.72^{\mathrm{a}}$ & $9.50^{b}$ & $\mathrm{H}_{0}$ Rejected \\
\hline Western & $31.88^{\mathrm{a}}$ & $9.50^{b}$ & $\mathrm{H}_{0}$ Rejected \\
\hline Volta & $17.72^{\mathrm{a}}$ & $9.50^{\mathrm{b}}$ & $\mathrm{H}_{0}$ Rejected \\
\hline Pooled & $11.70^{\mathrm{a}}$ & $9.50^{\mathrm{b}}$ & $\mathrm{H}_{0}$ Rejected \\
\hline \multicolumn{4}{|l|}{$\mathrm{H}_{0}: \mathrm{f}_{G R}\left(\mathrm{X} ; \beta_{\mathrm{GR}}\right)=\mathrm{f}_{A R}\left(\mathrm{X}: \beta_{A R}\right)=\mathrm{f}_{W R}\left(\mathrm{X}: \beta_{W R}\right)=\mathrm{f}_{V R}\left(\mathrm{X}: \beta_{V R}\right)$} \\
\hline Pooled Only & 248.02 & 76.05 & $\mathrm{H}_{0}$ Rejected \\
\hline
\end{tabular}


Table 1. Parameter estimates of the stochastic frontier and meta-frontier models

\begin{tabular}{|c|c|c|c|c|c|c|c|}
\hline Variable & Parameter & Accra (ML) & Ashanti (ML) & Western (ML) & Volta (ML) & Pooled (ML) & Meta (LP) \\
\hline Constant & $\beta_{0}$ & $-0.19(-0.11)$ & $2.15(3.93)$ & $0.26(3.10)$ & $0.12(0.61)$ & $0.65(3.69)$ & $1.12(2.12)$ \\
\hline LnFingerlings & $\beta_{1}$ & $0.18(2.49) * * *$ & $0.44(4.01)^{* * *}$ & $0.50(8.69) * * *$ & $0.26(3.71) * * *$ & $0.32(4.28) * * *$ & $0.39(2.58) * * *$ \\
\hline LnFeed & $\beta_{2}$ & $0.22(2.21)^{* *}$ & $0.25(9.04) * * *$ & $-0.13(-1.70) * *$ & $-0.22(-3.09) * * *$ & $-0.09(-1.13)$ & $0.06(0.31)$ \\
\hline LnLabour & $\beta_{3}$ & $0.20(1.35)$ & $-0.20(-2.72)^{* * *}$ & $0.44(5.53)^{* * *}$ & $0.39(3.58) * * *$ & $0.25(3.01) * * *$ & $0.22(3.03) * * *$ \\
\hline LnOC & $\beta_{4}$ & $0.99(3.72) * * *$ & $0.48(6.06)^{* * *}$ & $0.27(3.32)^{* * *}$ & $0.38(4.59) * * *$ & $0.48(6.09) * * *$ & $0.53(2.57)^{* * *}$ \\
\hline $1 / 2($ LnFing $) 2$ & $\beta_{5}$ & $-0.04(-0.28)$ & $-0.19(-4.30) * * *$ & $0.42(2.41) * *$ & $0.16(1.65) *$ & $0.01(0.01)$ & $0.07(0.89)$ \\
\hline $1 / 2($ LnFeed) 2 & $\beta_{6}$ & $-0.15(-1.98)^{*}$ & $-0.06(-3.01)^{* * *}$ & $0.08(0.47)$ & $0.08(0.71)$ & $-0.05(-0.71)$ & $0.17(1.79) *$ \\
\hline $1 / 2($ LnLabour) 2 & $\beta_{7}$ & $-0.15(-1.46)$ & $-0.06(-0.42)$ & $-0.21(-1.17)$ & $0.43(1.88) * *$ & $0.08(4.85) * * *$ & $0.27(1.85) *$ \\
\hline $1 / 2(\operatorname{LnOC}) 2$ & $\beta_{8}$ & $1.12(3.48) * * *$ & $0.02(0.20)$ & $-0.18(-0.86)$ & $-0.08(-0.70)$ & $0.02(2.85)^{* * *}$ & $0.10(0.70)$ \\
\hline LnFing*LnFeed & $\beta_{9}$ & $1.16(2.91) * * *$ & $0.14(1.97) * *$ & $-0.11(-0.97)$ & $-0.13(-2.34) * * *$ & $-0.01(-0.21)$ & $-0.03(-0.36)$ \\
\hline LnFing*LnLabour & $\beta_{10}$ & $0.37(2.00) * *$ & $-0.01(-0.17)$ & $0.14(2.66) * * *$ & $0.01(0.02)$ & $-0.03(-4.14) * * *$ & $-0.02(-4.32) * * *$ \\
\hline LnFing*LnOC & $\beta_{11}$ & $0.01(0.16)$ & $0.12(4.45) * * *$ & $0.07(0.77)$ & $0.04(0.45)$ & $0.02(0.69)$ & $0.02(0.27)$ \\
\hline LnFeed*LnLabour & $\beta_{12}$ & $-0.01(-0.03)$ & $0.01(0.13)$ & $0.15(0.71)$ & $-0.09(-0.76)$ & $-0.01(-0.82)$ & $-0.14(-1.99) * *$ \\
\hline LnFeed*LnOC & $\beta_{13}$ & $-0.16(-1.14)$ & $0.01(0.02)$ & $-0.09(-0.60)$ & $-0.05(-0.51)$ & $-0.02(-2.32) * *$ & $-0.08(-0.85)$ \\
\hline LnLabour*LnOC & $\beta_{14}$ & $-0.10(-0.70)$ & $-0.12(-0.86)$ & $0.59(0.32)$ & $-0.09(-0.79)$ & $-0.03(-2.43) * *$ & $0.06(0.61)$ \\
\hline \multicolumn{8}{|l|}{ Variance parameters } \\
\hline$\sigma^{2}=\left(\sigma_{u}^{2}+\sigma_{v}^{2}\right)$ & & 0.75 & 0.82 & 0.83 & 0.89 & 0.87 & \\
\hline$\gamma=\sigma_{u}^{2} /\left(\sigma_{u}^{2}+\sigma_{v}^{2}\right)$ & & 0.83 & 0.79 & 0.78 & 0.7 & 0.74 & \\
\hline Log likelihood & & -93.78 & -71.61 & -75.68 & -75.63 & -440.71 & \\
\hline
\end{tabular}

Note: Values in parenthesis are the t-statistics; OC denotes Other Cost; ML denotes Maximum Likelihood estimates and LP denotes Linear Programming estimates

* Denotes significance at $10 \%$

** Denotes significance at $5 \%$

$* * *$ Denotes significance at $1 \%$ 
Table 2. Output elasticities and return to scale from the regional and pooled frontiers

\begin{tabular}{|c|c|c|c|c|c|}
\hline Variables & Accra & Ashanti & Western & Volta & Pooled \\
\hline Fingerlings (Kg/Ha) & 0.18 & 0.44 & 0.5 & 0.26 & 0.32 \\
\hline Feed $(\mathrm{Kg} / \mathrm{Ha})$ & 0.22 & 0.25 & -0.13 & -0.22 & -0.09 \\
\hline Labour (Man-days/Ha) & 0.2 & -0.2 & 0.44 & 0.39 & 0.25 \\
\hline Other Cost $(\mathrm{GH} \not / \mathrm{Ha})$ & 0.99 & 0.48 & 0.27 & 0.38 & 0.48 \\
\hline RTS & 1.59 & 0.97 & 1.08 & 0.81 & 0.96 \\
\hline
\end{tabular}

RTS is the sum of all regional and pooled partial elasticities

0.87 for Greater Accra, Ashanti, Western, Volta regions and the Pooled data, respectively are significant at $1 \%$. The gamma estimates that measure the difference between the actual and the potential (frontier) output are computed to be $0.83,0.79,0.78,0.70$ and 0.74 , respectively for the Greater Accra, Ashanti, Western and Volta Regions and the combined data. These results mean that $83 \%, 79 \%, 78 \%, 70 \%$ and $74 \%$ of the deviations from the frontier are due to inefficiencies in the combination of input use and some farm level operations whereas noise factors that are not within the control of the farmers, contribute about $17 \%, 21 \%, 22 \%$, $30 \%$ and $26 \%$, respectively of deviations in the observed output from the frontier outputs. Some of the stochastic factors could be unfavourable weather factors, diseases and poaching.

The productivity response to the individual factor resources employed in the various regions and in the pooled data are presented in Table 2 . However, they are discussed as the mean output elasticities which are shown in Table 3. Under the Greater Accra region, the paper demonstrates that all the factor inputs per hectare have positive relationship with productivity. However, under the Ashanti region, all inputs have a positive influence on the output except labour/ha which exhibits a negative influence on output. It can be explained that labour in the Ashanti region may be over used resulting in the negative influence on output. Under the Western region, the Volta region and the combined data respectively, the study further reveals that fingerlings/ha, labour/ha and other cost/ha have a positive influence on output. However, feed/ha is estimated to have a negative influence on the production outcome. This indicates that as the quantity of feed increases by a percentage, the productivity of fish output falls by $0.13 \%, 0.22 \%$ and $0.09 \%$, respectively in Western, Volta and the pooled data. Thus, care must be taken in the quantity of feed applied per hectare in these regions. This finding is also revealed by Crentsil \& Essilfie (2014).

It is evident from the paper that summation of the partial elasticities with respect to each input used in production is 1.59, 0.97, 1.08, 0.81 and 0.96 for Greater Accra, Ashanti, Western and Volta regions as well as the pooled, respectively (Table 3 ). These are the returns-toscale (RTS) coefficients, also known as the function coefficients or scale output elasticities. With RTS values of 1.59 and 1.08 , it can be inferred that $1 \%$ rise in all factor inputs may lead to $1.59 \%$ and $1.08 \%$ increase in the level of fish farm output in the Greater Accra and Western regions, accordingly. This implies, fish farms in these regions are operating on a small scale (increasing return to scale) and there is more room for expansion to take advantage of economies of scale. Furthermore, with RTS values of $0.97,0.81$ and 0.96 , it can be inferred that a percentage increase in all input factors results in a $0.97 \%, 0.81 \%$ and $0.96 \%$ increase in the level of output for the farms in the Ashanti and Volta regions as well as the pooled data. This implies that fish farms in the Ashanti and Volta regions together with the pooled may be operating on a large scale (decreasing returns to scale) and therefore productivity can only be increased if quantities of some inputs such as labour and feed are reduced to the optimal level.

A summary of the regional gap ratio (RGR), regional technical efficiencies (TE) and the meta-frontier efficiency scores (TE*) are presented in Table 4. Fish farms gain directly from increases in technical efficiency (TE) which translates into an improvement in profits and household financial gains. Table 4 reveals that the average technical efficiencies obtained from the regional frontiers are $0.72,0.61,0.68,0.82$ and 0.70 for Greater Accra, Ashanti, Western and Volta areas and the pooled data, respectively. The findings show that averagely, fish farms in the Greater Accra region are $28 \%$ below their group frontier, whereas the farms in the Ashanti, Western and Volta regions and the pooled are $39 \%, 32 \%, 18 \%$ and $30 \%$ below their group frontiers, respectively. This further means that if the fish farms in the regions can attain maximum efficiency scores, they may have to improve on their current performance by addressing some inefficiency issues. The RGR figures can be understood as the average regional difference between the meta-frontier and the individual frontiers whilst taking into consideration the available inputs (Battese, Rao, \& O'Donnell, 2004; and Binam, Gockowski \& Nkamleu, 2008). Results in Table 4 reveal that the RGRs for the Greater Accra, Ashanti, Western and Volta regions are $0.76,0.70,0.73$ and 0.78 , respectively. These results imply that on the average if producers in Greater Accra, Ashanti, Western and Volta are to be operating on their regional efficiency frontiers, they may enhance production output by $24 \%, 30 \%, 27 \%$ and $22 \%$ respectively if such farms were to adopt the most efficient potential meta-regional practices. These figures are much smaller in the Volta (22\%) and Greater 
Table 3. Summary statistics of technical efficiency scores and regional gap ratios

\begin{tabular}{|c|c|c|c|c|c|}
\hline Region/Statistic & & Mean & Minimum & Maximum & St. Deviation \\
\hline \multicolumn{6}{|c|}{ Greater Accra Region } \\
\hline & Regional TE & 0.72 & 0.05 & 0.9 & 0.26 \\
\hline & Regional Gap Ratio & 0.76 & 0.04 & 0.94 & 0.22 \\
\hline & Meta-frontier TE* & 0.55 & 0.03 & 0.89 & 0.21 \\
\hline \multicolumn{6}{|l|}{ Ashanti Region } \\
\hline & Regional TE & 0.61 & 0.02 & 0.98 & 0.24 \\
\hline & Regional Gap Ratio & 0.7 & 0.07 & 0.99 & 0.26 \\
\hline & Meta-frontier TE* & 0.43 & 0.1 & 0.83 & 0.21 \\
\hline \multicolumn{6}{|l|}{ Western Region } \\
\hline & Regional TE & 0.68 & 0.06 & 0.96 & 0.19 \\
\hline & Regional Gap Ratio & 0.73 & 0.2 & 0.99 & 0.2 \\
\hline & Meta-frontier TE* & 0.5 & 0.03 & 0.81 & 0.19 \\
\hline \multicolumn{6}{|l|}{ Volta Region } \\
\hline & Regional TE & 0.82 & 0.01 & 0.93 & 0.26 \\
\hline & Regional Gap Ratio & 0.78 & 0.12 & 0.99 & 0.24 \\
\hline & Meta-frontier TE* & 0.64 & 0.01 & 0.86 & 0.24 \\
\hline \multicolumn{6}{|l|}{ Pooled } \\
\hline & All Regional TE & 0.7 & 0.23 & 0.99 & 0.13 \\
\hline & Regional Gap Ratio & 0.75 & 0.01 & 0.99 & 0.24 \\
\hline & Meta-frontier TE* & 0.53 & 0.04 & 0.99 & 0.24 \\
\hline
\end{tabular}

Note: The linear programming estimates for the Meta-frontier coefficients are used in this table.

Accra (24\%), demonstrating that the present application of knowledge in the study regions along with regional specific environments are near the potential possibility frontier. This further implies that farms in the Volta and Greater Accra regions are likely to attain the potential fish farm output faster than their counterparts in the Ashanti and Western regions.

Furthermore, the mean TE scores for the fish farmers in Volta and Greater Accra relative to the metafrontier are 0.64 and 0.55 , respectively as against 0.43 and 0.50 meta-frontier efficiency levels for the farms in the Ashanti and Western regions, respectively. This implies that averagely, farms in Volta and Greater Accra regions are more technically efficient than those in the Ashanti and Western regions. Climate-data.org notes the average annual temperature and rainfall in Greater Accra to be $\left(26.8^{\circ \mathrm{C}}, 895 \mathrm{~mm}\right)$; Volta $\left(27.0^{\circ \mathrm{C}}, 1478 \mathrm{~mm}\right)$; Ashanti (26.3 ${ }^{\circ}$; $\left.1448 \mathrm{~mm}\right)$; and Western $\left(26.0^{\circ}\right.$, $1506 \mathrm{~mm})$. According to Opeyemi, Oluwatosin, Owoeye, \& Owoey (2016), low temperature and high rainfall may increase the relative humidity of the area. Ali \& Nakamura (1999) reveal that high relative humidity can have negative consequences on the metabolism of fish which may reduce the productivity and efficiency of fish farm output in the Ashanti and the Western regions as compared to farms in Greater Accra and Volta regions. Additionally, fish farms in the Volta and the Greater Accra predominantly adopt the use of cage ponds for their operation and this system have a constant supply of water nutrient throughout the production season from lakes and rivers to enhance productivity and efficiency of operation. These findings further suggest that farms in the Ashanti and Western regions have to improve their knowledge on managerial practices especially the use of cage ponds on available lakes and rivers in order to match up with their Volta and Greater Accra regional counterparts.

Figure 2 illustrates a representation of the metafrontier for the fish farms in the four regions. Given the level of resources at the disposal of fish farms in each of the regions, a potential output of $5,157 \mathrm{Kg} / \mathrm{ha}$ may have been produced in the Volta region if the fish farms in the region are fully efficient. Farms in the Greater Accra, Western and Ashanti regions under the given level of resources can also produce a total of $4,816 \mathrm{Kg} / \mathrm{ha}, 3,977$ $\mathrm{Kg} / \mathrm{ha}$ and $3,588 \mathrm{Kg} / \mathrm{ha}$, respectively. However, though the paper observes that fish farms in the four regions are performing below their regional potential, comparatively, farms in the Volta and Greater Accra regions are performing more efficiently than their counterparts in the Western and Ashanti regions. This implies that the potential to still increase output to meet the meta-frontier output is easier in Volta and Greater Accra regions than Western and Ashanti regions. A similar framework has been developed in Binam, Gockowski \& Nkamleu (2008).

The estimated technical efficiency levels among farms in each of the four regions are not sufficient to draw recommendations. Thus identifying the sources of variation in the TE scores as demonstrated in Table 5 is paramount. The results show that the coefficient of age is negative and significant under Greater Accra and Volta regions as well as the pooled data. This implies that age positively influence technical efficiency of farms found in these regions. In other words, farmers that are older are relatively efficient in relation to the younger ones. This result is contrary to the finding of Saiyut, Bunyasiri, Sirisupluxana, Mahathanaseth (2018) who note that 
Table 4. Inefficiency model estimates

\begin{tabular}{|c|c|c|c|c|c|c|}
\hline Variable & Parameter & Greater Accra & Ashanti & Western & Volta & Pooled \\
\hline Constant & $\delta_{0}$ & $-0.49(-0.28)$ & $5.91(6.60) * * *$ & $3.60(4.09) * * *$ & $-1.74(-0.70) *$ & $3.59(1.41)^{* *}$ \\
\hline Age & $\delta_{1}$ & $-0.01(-3.52) * * *$ & $0.03(2.13) * *$ & $0.10(1.20)$ & $-0.05(-2.36) * *$ & $-0.22(-2.24)^{* *}$ \\
\hline Gender & $\delta_{2}$ & $-2.03(-2.47)^{* *}$ & $0.37(0.94)$ & $-0.15(-0.55)$ & $-3.06(-2.44) * *$ & $-0.41(-3.09) * * *$ \\
\hline Education & $\delta_{3}$ & $-0.13(-4.58)^{* * *}$ & $-0.13(-3.73) * * *$ & $0.16(0.87)$ & $-0.01(-0.24)$ & $0.23(1.35)$ \\
\hline Household Size & $\delta_{4}$ & $-0.21(-1.78)^{*}$ & $-0.23(-4.32) * * *$ & $0.30(0.81)$ & $-0.01(-0.29)$ & $0.03(0.80)$ \\
\hline Major Occupation & $\delta_{5}$ & $-1.05(-2.63) * * *$ & $-0.01(-0.01)$ & $0.99(2.11)^{* *}$ & $-0.20(-1.77)^{*}$ & $-5.79(-3.02) * * *$ \\
\hline Pond Type & $\delta_{6}$ & $-3.16(-3.40)^{* * *}$ & $-4.07(-2.34)^{* *}$ & $-2.42(-1.12)$ & $-0.85(-3.43) * * *$ & $-6.82(-3.95) * * *$ \\
\hline Ownership & $\delta_{7}$ & $-0.87(-0.95)$ & $-1.07(-2.57) * * *$ & $0.42(1.41)$ & $-1.27(-2.46) * *$ & $-8.58(-4.97) * * *$ \\
\hline FFA & $\delta_{8}$ & 1. $35(2.83) * * *$ & $-1.73(2.77) * * *$ & $0.89(3.11)^{* * *}$ & $-1.51(1.98) * *$ & $-2.81(-1.24)$ \\
\hline Extension & $\delta_{9}$ & $-1.56(-2.86) * * *$ & $-1.30(-1.78)^{*}$ & $-3.27(-6.48) * * *$ & $-1.52(-1.98)^{* *}$ & $-7.43(-3.45) * * *$ \\
\hline Market Access & $\delta_{10}$ & $0.34(0.74)$ & $-1.55(2.91)^{* * *}$ & $-2.16(-7.84)^{* * *}$ & $0.451(0.55)$ & $-18.42(-5.32) * * *$ \\
\hline
\end{tabular}

Note: Values in parenthesis are the t-statistics; FFA denotes Fish Farmers Association.

* Denotes significance at $10 \%$.

** Denotes significance at 5\%.

*** Denotes significance at 1 
older farmers above 60 years operate with less efficiency in Thai Agriculture. However, results from the current paper affirm the findings of Binam, Gockowski, \& Nkamleu (2008) that the older farmers are more efficient than the younger ones. Their paper note that aged farmers may be more efficient due to their good managerial skills, acquired over time. Besides, given the capital intensive nature in fish farming, it could be said that farmers in early period of life are quite insufficient in resources and may not be better positioned to acquire adequate inputs or implement certain production practices timely to enhance efficiency.

Nonetheless, the result estimates suggest the contrary for the Western region and Ashanti regions indicating that older and assumed experienced farmers produce with less efficiency compared to the younger farmers though the relationship is weak in the Western region. The increase in the inefficiency by the older farmers can be ascribed to their conservative nature in these regions. These farmers might be self-satisfied with their usual husbandry patterns over the past years and may not be willing to adopt the use of advanced practices.

The paper finds that gender is estimated to be negative under the pooled data and all the regions except the Ashanti region. However, this finding is only significant under the Greater Accra region, the Volta region and the pooled data, indicating that female farmers are less efficient compared to their male similitudes. It further reveals that male fish farmers in the Greater Accra region, the Volta region and the pooled data are more technical efficiency than the female farmers. The finding is consistent with Addison,
Ohene-Yankyera, \& Fredua-Antoh (2016) and can be explained that female farmers are more likely to engage in other income generating ventures that may compete with their fish farms for the limited resources available to them. In the long run, female fish farmers must be encouraged to focus more on their fish farming activities in order to enhance their efficiency and productivity levels.

Years of formal education is found to be consistent with the expected negative sign for all the regions except Western region and the pooled data, however, the estimates are significant for Greater Accra and the Ashanti regions. This implies that all other things being equal, attaining formal education enable farmers to better understand the use of new technologies, enhanced farming practices and extension programs geared towards improving efficiency levels in production in the Greater Accra and Ashanti regions. This confirms the findings of Anang, Bäckman, \& Sipiläinen (2016) who note that farmers with higher number of years of formal education incline to be relatively technically efficient in their farming activities, presumably, due to their edge in acquiring technical knowledge. Nyagaka, Obare, Omiti, \& Ngoyo (2010) note a positive effect of education on efficiency among Ghanaian and Nigerian farm producers. Nonetheless, the paper in corroboration with Onuche, Ali, \& Isaac (2015) reveals that education negatively affect technical efficiency of production in the Western region and in the combined data. However, relationships are found to be weak. Since fish farming activities requires a large number of labour, the size of fish farmers' households is expected to contribute to the labour supply to enhance

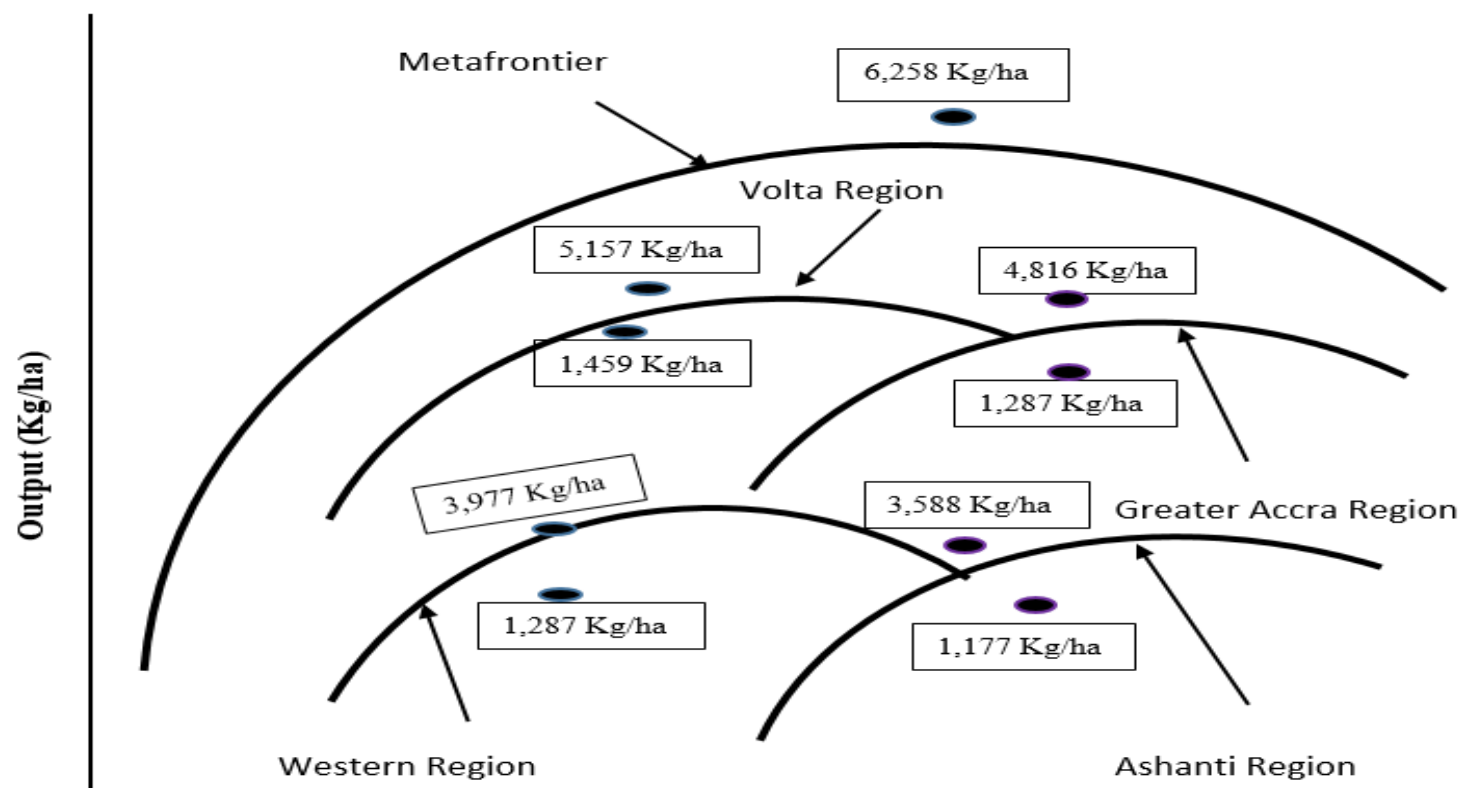

Inputs (Individual units/ha)

Figure 2. Graphical representation of the meta-frontier for the fish farmers. 
efficiency. The results from the Greater Accra and Ashanti are found to be consistent with this assertion. The implication is that large household sizes contribute to the timely supply of labour for fish farming in these regions leading to improved productivity and efficiency as also reveal by Ogundari \& Akinbogun (2010). Western, Volta and the pooled data however, have a negative but weak influence on efficiency with respect to household size.

The coefficient of major occupation is found to be negative under Greater Accra, Ashanti, Volta and the pooled data, though there is a weak relationship in the Ashanti region. This implies, respondents who commit their entire working time to fish farming in these regions are more technically efficient compared to their counterparts who practice fish farming on part time bases. This result confirms the findings of Brümmer (2001) who argue that full time private farmers in Slovenia tend to allocate many resources in order to achieve high efficiency. The paper nonetheless reveals that full time fish farmers negatively and significantly influence the efficiency of fish farming in the Western region, meaning that part time operators are more efficient compared to their counterpart full timer farmers in this region. It is believed that part time fish farmers in the western region who also either work in the cocoa, mining or the oil industries could have additional funds to afford fish farm inputs and other efficiency enhancing technologies compared to their counterpart full time fish farmers.

The parameter estimate of pond type is found to be significantly negative in all the regions and pooled data even though the relationship is weak in the Western region. This finding is consistent with Iliyasu, Mohamed, \& Terano (2016) and it implies that cage pond users tend to be more efficient than earth pond operators because of the advantage of the limitless amount of water supply which provides immense amounts of oxygen that is significant for fish farming. Floating feed which is normally used in the cage system of fish farming prevents silting, provides efficient fish feeding and serves as health checks.

Ownership of fish farm is found to improve the efficiency levels in the Greater Accra, Ashanti and Volta regions and the pooled data, although the relationship is weak in the Greater Accra. However, it is observed to reduce the efficiency levels of fish farmers in the Western region with weak significance. These findings can imply that fish farms in the pooled data, Ashanti and in Volta regions owned and operated by the farmers themselves tend to perform better than farms managed by people other than the owners themselves. Addai \& Owusu (2014) note that the implementation of innovative farming practices is quite difficult with nonfarm ownership.

Fish farmers association is revealed to be negative and significant under Ashanti and Volta regions but weak in the pooled data implying an increase in efficiency levels of farms in these regions though the relationship is weak for the pooled data. However, the reverse is found in relation to the efficiency levels of their counterpart farms in the Greater Accra and Western regions, indicating that farmers in the Ashanti and Volta regions who are members of fish farmers association may be better positioned to have access to technical knowledge, labour and financial support to enhance their efficiency of production. Unexpectedly, it is believed that farmers in Greater Accra and Western regions may not be receiving enough group benefit to enhance efficiency.

The paper also demonstrates that access to extension is negative and significant across all regions and in the pooled data, indicating that extension service enhances the efficiency of farms in all the four regions. This finding implies that an increase in farmers' access to extension services with fish farming-specific information is expected to increase the productivity and efficiency of the fish farms in the area of study. This is consistent with the results of Binam, Gockowski, \& Nkamleu (2008), Nyagaka, Obare, Omiti, \& Ngoyo (2010) and Anang, Bäckman, \& Sipiläinen (2016). This outcome reveals that effective extension services and supervision enhanced farmers' production efficiency.

Easing the market challenges of fish farms may enhance the timely recovery of investment after harvesting of fish and this may increase access to inputs during the production process and hiring of labour for production activities. Consistent with the work of Cobbina \& Eiriksdottir (2010), results from this paper show that farms in Ashanti, Western regions and in the pooled data with access to ready market (mostly at farm gate) are more technically efficient than those with inconsistent access to ready market. This showed that access to ready market is very vital in improving the performance of fish farms in these regions. The results are contrary in Greater Accra and in the Volta regions though the relationships are weak.

\section{Conclusion}

The stochastic meta-frontier model is employed in the estimation of the productivity and technical efficiency differentials among fish farms in the Greater Accra, Ashanti, Western and Volta regions of Ghana. The meta-frontier model adopted allows the assessment of regional gap ratios by decomposing the results whilst taking into consideration both the regional or individual stochastic frontiers and the meta-frontier. It also supports the school of thought that average productivity prospects and technical efficiency relativity give further account unlike the analysis based only on the separate regional stochastic frontiers.

Grounded on the findings of the study, the paper demonstrates that the meta-frontier model is the most appropriate technique compared to the conventional stochastic frontier model for unbias estimates. Unlike 
the Cobb-Douglas production function, the translog model is identified as the best functional form for the data. The paper reveals that fish farms in the Volta and Greater Accra regions are closer to the best practice meta-regional output than their counterparts in the Ashanti and Western regions of Ghana. Findings from the meta-frontier efficiency scores reveal that fish farms in the Volta and Greater Accra regions are relatively technically efficient in comparison to farmers in the Ashanti and Western regions of Ghana. Therefore, the paper establishes that the possibility to reach the maximum potential output is higher in the Volta and Greater Accra regions than in the Ashanti and Western regions of Ghana. It is also discovered from the Returns to Scale (RTS) computed that productivity increased more proportionately (increasing return to scale) with one percentage increase in the level of all input factors employed by fish farms in the Greater Accra and Western regions. However, productivity increased less proportionately (decreasing return to scale) with a percentage increase in all input factors employed by farms in the Volta, Ashanti regions and in the pooled data.

Finding further demonstrates that fish farms in the four regions are performing below their regional potential. Notwithstanding, the paper comparatively establishes that fish farms in the Volta and Greater Accra regions are performing technically efficient than their counterpart fish farms in the Western and Ashanti regions. This indicates that the potential to increase fish farm yields to the meta-frontier output is more prominent in the Volta and Greater Accra regions compared to farms in the Western and Ashanti regions.

The paper additionally establishes the presence of inefficiencies among the fish farmers in the regions studied. Based on the findings from the individual regions, the paper shows that the combined influence of exogenous variables included in the inefficiency model are able to explain the level and variability in fish farm output, although estimates of some factors are insignificant. Findings from the combined data reveal that age of primary decision maker, gender, major occupation, pond type, farm ownership, extension, and access to market positively influence efficiency of fish farmers. This demonstrates that if fish farmers in the four regions are able to handle these factors well, they will be able to increase their production efficiencies. The paper also shows that other factors such as education and household size are found to decrease the efficiencies of fish farms in the pooled data.

Against these findings, the paper recommends that fish farms in Greater Accra and Western regions must endeavour to increase their scale of production by embracing measures that will enhance their productivity through the application of effective managerial practices on their farms to take advantage of long run reduction in per unit cost of production (economics of scale). Further, this paper encourages farmers in the
Ashanti and Western regions to increase their learning on managerial practices pertaining to cage system on available lakes and rivers and also consider the use of harsh weather resistive species in order to match the production efficiency with their Volta and Greater Accra regional counterparts

\section{Acknowledgements}

The study is funded by the Office of Research, Innovation and Development (ORID), University of Ghana, Legon. Supervision of the project in terms of design, field survey and data management is done by ORID. However, the content of the paper is the responsibility of the authors

\section{References}

Addai, K.N., \& Owusu, V. (2014). Technical efficiency of maize farmers across various agro ecological zones of Ghana. Journal of Agriculture and Environmental Sciences, 3(1), 149-172.

Addison, M., Ohene-Yankyera, K., \& Fredua-Antoh, E. (2016). Gender role, input use and technical efficiency among rice farmers at Ahafo Ano North District in Ashanti Region of Ghana. Journal of Food Security, 2016, Vol. 4, No. 2, 27-35

Akuffo, A. S. \& Quagrainie, K. K. (2019). Assessment of Household Food Security in Fish Farming Communities in Ghana. Sustainability 2019, 11(10), 2807; https://doi.org/10.3390/su11102807

Ali, F., and Nakamura, K. (1999). Effect of Temperature and Relative Humidity on the Tolerance of the Japanese clam, Ruditapes philippinarum (Adams \& Reeve), to Air Exposure. Aquaculture Research 30 (1999): 629-636.

Amenyogbe E, Chen G, Wang Z, Lin M, Lu X, Atujona, D., \& Abarike, E.D. (2018). A Review of Ghana's Aquaculture Industry. J Aquac Res Development 9: 545. doi: 10.4172/2155-9546.1000545

Anang, B. T., Bäckman, S., \& Sipiläinen, T. (2016). Technical efficiency and its determinants in smallholder rice production in northern Ghana. The Journal of Developing Areas, 50(2), 311-328.

Battese, G.E., Rao, D.S.P. \& O'Donnell, C. J. (2004). A Meta Frontier Production Function for estimation of technical efficiencies and technology potentials for firms operating under different technologies. Journal of Productivity Analysis, 21, 91-103.

Battese, G.E. \& Coelli, T.J. (1995). A Model for Technical Inefficiency Effects in a Stochastic Frontier Production Function for Panel Data. Empirical Economics, 20, 325332.

Battese, G.E. \& Coelli, T.J. (1992). "Frontier Production Functions, Technical Efficiency and Panel Data: With Application to Paddy Farmers in India". Journal of Productivity Analysis, 3, 153-169.

Binam J. N., Gockowski J. \& Nkamleu G.B. (2008). Technical efficiency and productivity Potential of cocoa farmers in West Africa countries. The Developing Economics, 3: 242-263.

Brümmer, B. (2001). Estimating confidence intervals for technical efficiency: the case of private farms in Slovenia. 
European review of agricultural economics, 28(3), 285306.

Brümmer, B. (2015). Stochastic frontier analysis using SFAMB for Ox. Department of Agricultural Economics and Rural Development, Georg-August University, Goettingen, Germany.

Climate-data.org. https://en.climate-data.org/africa/ghana121/, (Cited 24 August 2020).

Cobbina, R. \& Eiriksdottir, K. (2010). Aquaculture in Ghana: Economic Perspectives of Ghanaian Aquaculture for Policy Development. UNU-Fisheries Training Programme, Final Project, 1-47.

Coelli, T. J., \& Battese, G. E. (1996). Identification of factors which influence the technical inefficiency of Indian farmers. Australian Journal of Agricultural Economics 40:103-128.

Crentsil, C. \& Essilfie, F. L. (2014). Measurement of technical efficiency of smallholder fish production in Ghana: A stochastic frontier approach. Journal of Development and Agricultural Economics, 6(5), 203-211. doi:10.5897/JDAE12.146.

FAO (2016). Fishery and Aquaculture Country Profile Fact Sheets. In: Food and Agriculture Organization (FAO) of the United Nations Fisheries Division [online]. Rome. Updated 2016. [Cited 24 August 2020]. http://www.fao.org/fishery.

Hayami, Y. \& Ruttan V. W. (1970). Agricultural productivity differences among countries. American Economic Review, 40, 895-911.

Iliyasu, A., Mohamed, Z. A., \& Terano, R. (2016). Comparative analysis of technical efficiency for different production culture systems and species of freshwater aquaculture in Peninsular Malaysia. Aquaculture Reports 3(2016) 51-57.

Kodde, D.A., \& Palm, F.C. (1986). Wald criteria for jointly testing equality and inequality restrictions. Econometrica 54:1243-1248.
Nyagaka, D.O., Obare G.A., Omiti J.M. \& Ngoyo W. (2010). Technical efficiency in resource Use: evidence from smallholder Irish potato farmers in Nyandaura North District, Kenya. Africa Journal of Agricultural Research, 5: 1179-1186.

O'Donnell, C.J., Rao, D.S.P. \& Battese, G.E. (2008). 'Metafrontier frameworks for the study of firm-level efficiencies and technology ratios', Empirical Economics, 34(2):231-255.

Ogundari, K. \& Akinbogun, O.O. (2010). Modelling Technical Efficiency with Production Risk : A Study of Fish Farms in Nigeria. University of Kiel, 25, 295-308.

Onuche, U., Ali, S.O., \& Isaac, J.T. (2015). Technical efficiency estimates and the role of formal education: Evidence from catfish firms in ljumu Local Government Area of Kogi State, North Central, Nigeria. Agrosearch, 15(2), 107-117.

Onumah, J.A., Al-Hassan, R.M., \& Onumah, E.E. (2013). Productivity and technical efficiency of cocoa production in Eastern Ghana. Journal of Economics and Sustainable Development, 4(4), 106-117.

Onumah, E.E., Brümmer, B. \& Horstgen-Schwark, G. (2010). Elements Which Delimitate Technical Efficiency of Fish Farms in Ghana. Journal of the World Aquaculture Society Vol. 41, No. 4.

Opeyemi, S.R., Oluwatosin, M.M., Owoeye, A.O., and Owoey, R.S. (2016). Effects of Changes in Temperature, Rainfall and Relative Humidity on Banana Production in Ondo State, Nigeria. World Scientific News 44 (2016): 191-202

Quagrainie, K. \& Chu, J. (2019). Determinants of Catch Sales in Ghanaian Artisanal Fisheries. Sustainability 2019, 11, 298; http://doi.org/10.3390/su11020298

Saiyut, P., Bunyasiri, I., Sirisupluxana, P., \& Mahathanaseth, I. (2018). The impact of age structure on technical efficiency in Thai agriculture. Kasetsart Journal of Social Sciences 40 (2019) 539-545. 